\title{
IDEAS QUE RIMAN
}

\author{
Maximiliano Valerio López* \\ Universidad Federal Fluminense, Brasil
}

\section{Resumen}

A partir de Octavio Paz quien señala una relación entre el ritmo del lenguaje y las ideas, es posible cuestionar una de las direcciones de la filosofía occidental como es la de distanciarse del mito y de la poesía y acogerse al criterio de las ideas claras y distintas y, al principio de no contradicción. El ritmo del lenguaje y el mito, en la filosofía, sin embargo, se mantienen como un trasfondo y la sabiduría Oriental ha permanecido cercana a la poesía.

Palabras clave: pensar filosófico, sabiduría y poesía.

\begin{abstract}
Ideas that rhyme

Studying the texts of Octavio Paz, who points out a relationship between language rhythm and ideas, it is possible to question one of the directions of Western philosophy which consists of taking a distance from myth and poetry, and residing under the criteria of clear and distinct ideas, and the principle of non contradiction. In philosophy, the rhythm of language and myth have remained in the a background, however in Eastern wisdom has remained close to poetry.
\end{abstract}

Key Words: philosophical thinking, wisdom, poetry.

\section{INTRODUCCIÓN}

Escribo este trabajo, conmovido por una bellísima frase de Octavio Paz, que resuena en mí con la fuerza de una evidencia.

Sentimos que las ideas riman. Entrevemos entonces que pensamientos y frases son también ritmos, llamadas, ecos. Pensar es dar la nota justa, vibrar apenas nos toca la honda luminosa. (Paz, 2003, p. 75-76).

Escribo sobre esta frase, pienso en ella, la saboreo, intento interpretarla, no sólo como se interpretan las palabras, sino también al modo que se interpretan las melodías. Es precisamente eso lo que está en juego. Presento entonces esta breve meditación en cuatro movimientos pensantes, en cuatro consideraciones movientes.

*maximilianolopez@vm.uff.br 


\section{Primer movimiento: Ideas que riman}

Que las ideas rimen es un hecho tan fascinante como escandaloso. Pues inicialmente parece contrariar una concepción del pensamiento que se volvió canónica en la cultura occidental, según la cual, las ideas no riman, porque la rima pertenece a una dimensión musical del lenguaje y la racionalidad no se organiza de acuerdo con principios musicales. La racionalidad depende de las formas claras y distintas que se apoyan en el principio de no contradicción, aquel que determina que una cosa no puede ser y no ser al mismo tiempo y en el mismo sentido. Lo que está en juego en la afirmación del poeta y ensayista mexicano es la propia naturaleza del pensamiento. Afirmar que las ideas riman implica introducir un principio rítmico en el pensamiento que cuestiona la idea dominante que tenemos de él. Según Paz:

El ritmo no solamente es el elemento más antiguo y permanente del lenguaje, sino que no es difícil que sea anterior al habla misma. En cierto sentido puede decirse que el lenguaje nace del ritmo; o, al menos, que todo ritmo implica o prefigura un lenguaje. Así, todas las expresiones verbales son ritmo, sin excluir las formas más abstractas o didácticas de la prosa. (...) Por la violencia de la razón las palabras se desprenden del ritmo; esa violencia racional sostiene en vilo la prosa, impidiéndole caer en la corriente del habla en donde no rigen las leyes del discurso sino las de la atracción y la repulsión. [...]. Dejar el pensamiento en libertad, divagar, es regresar al ritmo; las razones se transforman en correspondencias, los silogismos en analogías y la marcha intelectual en fluir de imágenes. Pero el prosista busca la coherencia y la claridad conceptual. Por eso se resiste a la corriente rítmica que, fatalmente, tiende a manifestarse en imágenes y no en conceptos. (Paz, 2003, p. 89).

En las palabras de Octavio Paz, vemos surgir una tensión entre el concepto y el ritmo. El fondo del lenguaje es ritmo, pero la prosa lucha contra esa corriente rítmica para alcanzar una dimensión conceptual. El ritmo está presente en toda forma verbal, pero sólo se manifiesta plenamente en la poesía. La prosa se eleva sobre la dimensión rítmica mediante un esfuerzo de la conciencia, pero ni bien se relaja, las palabras vuelven, como movidas por una fuerza de gravedad, a su dimensión musical. Eso se hace evidente en experiencias como el sueño, el delirio o la hipnosis o en ejercicios como la escritura automática o ciertas formas de la improvisación teatral. En el fondo de las gramáticas, el habla respira como el resto de los seres vivos, movida por el flujo y reflujo del Universo. Por debajo del principio racional, que ordena y distribuye las palabras, el habla es gobernada por el ritmo. Sólo a través de una violencia ejercida por el análisis gramatical puede la lengua descomponerse en palabras. La tensión entre prosa y poesía se expresa en una lucha continua (agon) entre la racionalidad, entendida como sujeción al principio de no contradicción, y el ritmo.

El idioma es una totalidad indivisible, nos dice Paz, y su menor unidad no es la palabra sino la frase significante. Nadie habla con palabras sueltas sino con frases. Observamos como las personas que no saben leer ni escribir, aquellos que desconocen la gramática, hacen las pausas en los lugares apropiados, es decir, cuando una frase termina o cambia de intensidad. Su percepción del lenguaje es musical y no gramatical. Es el ritmo y no la métrica lo que sustenta el sentido de la frase. Sentido y ritmo se confunden. 
El lenguaje está habitado por una tensión trágica entre la forma de las ideas (claras y distintas) y una dimensión musical, rítmica, que escapa al principio de no contradicción. La corriente rítmica tiende, fatalmente, a manifestarse en imágenes y no en conceptos, como lo señala Paz. El concepto destaca, recorta, escoge, reúne y organiza; de la misma forma, la imagen poética somete a unidad la pluralidad de lo real, aun cuando sea indiferente a la no contradicción; la imagen poética llega al extremo de afirmar la identidad de los contrarios. Ella no dice solamente "sus ojos son como soles atroces", ella dice "sus ojos son soles atroces". La imagen poética no sólo dice "esto es como aquello", sino "esto es aquello". Lo cual resulta escandaloso para el principio de no contradicción, piedra angular sobre la cual Occidente ha edificado su cultura. Para conjurar tal peligro, la poesía debió ser desterrada de la realidad y condenada a vivir entre fantasmas. Condenada a no decir lo que es, sino lo que podría ser. Su dominio fue limitado a lo "imposible verosímil". En definitiva, la poesía fue declarada impotente en relación a la verdad.

\section{Segundo movimiento: mito y filosofía}

Según nos cuentan los manuales la filosofía nace del mito. Tal emergencia se hace posible gracias al poder clarificador del principio de no contradicción, pieza fundamental del pensamiento griego. Este principio permitió despojar al mundo de su ambigüedad mítica, tornándolo claro y distinto, marcando así el surgimiento de la filosofía. Esbozado por Parménides y teorizado posteriormente por Platón y Aristóteles, el principio de no contradicción disipa la ambigüedad del mundo mítico, donde cada rasgo se confunde con su contrario. Así, por obra de este principio, los contrarios se vuelven antagónicos y en virtud de esa rivalidad, tan cara al pensamiento griego, el mundo ondulante de las potencias míticas sede su lugar a un mundo dicotómico, estable y definido. Por obra de semejante principio, la imagen mítica del mundo se torna concepto, haciendo posible la constitución de un discurso riguroso de lo verdadero.

Para entender la intuición de Octavio Paz que procuro interpretar, es menester no considerar esta emergencia de la filosofía como resultado de una evolución. No se trata de una génesis temporal, por lo menos no en un sentido lato. Sería más adecuado decir que no se trata de una génesis cronológica. La filosofía nace del mito, pero no en el sentido evolutivo, que se tornó común en la representación moderna (y colonial) del tiempo. La filosofía nace del mito como una figura emerge de un fondo. La figura no supera al fondo, sino que lo necesita para continuar siendo figura. La figura se destaca del fondo y, sin embargo, no puede prescindir de él. No se trata de una evolución, sino de una emanación.

Esta relación es asimétrica, dado que el fondo no necesita de la figura, pues es infinito, se basta a sí mismo, en cuanto la figura no puede prescindir del fondo para continuar siendo lo que es. El fondo es la condición de posibilidad de la figura. En ese sentido el mito tiene anterioridad ontológica y no temporal en relación a la filosofía. No hay evolución del mito a la filosofía porque para que eso fuese posible ambos deberían formar parte de un tiempo continuo. No obstante, mito y filosofía difieren en naturaleza y no simplemente en grado. Cada uno posee una temporalidad propia, cualitativamente diferente. 
El mito nos remite para un tiempo arquetípico, dice Octavio Paz, tiempo originario, puro, rítmico, mientras que la filosofía nos remite a un tiempo abstracto, homogéneo, sucesivo, cronológico. Ambos tiempos difieren cualitativamente y no cuantitativamente. Entre uno y otro no hay acrecentamientos o pérdidas cuantitativas, sino un salto, una discontinuidad. El tiempo que miden los relojes y los calendarios no es propiamente el tiempo sino una forma de representación del tiempo, un recorte una medida. Como dice Aristóteles en el libro IV de la Física, el tiempo es "medida del movimiento según el antes y el después". Este tiempo-medida, del que nos habla el filósofo es lo que podríamos también llamar el tiempo empírico, aquel que rige nuestras actividades cotidianas, permitiendo organizar el mundo social según medidas homogéneas y universales de tiempo. La medición del tiempo es posible por la distinción racional, por la abstracción, reducción esta que se apoya en la disyunción exclusiva, propia del principio de no contradicción. Pero no se debe confundir el tiempo con su representación. Toda abstracción es una reducción que intenta esclarecer la ambigüedad originaria del tiempo, pero no es el tiempo en sí. "La temporalidad es anterior a la representación y lo que la hace posible" (PAZ, 2003, p. 80).

Gilles Deleuze ha retomado en diferentes partes de su obra este asunto, teniendo como telón de fondo la obra de Henri Bergson. Para escapar de la idea de una superación cronológica de un tiempo en relación al otro, ha rechazado las categorías tradicionales de lo "posible" y lo "real" prefiriendo usar en su lugar las de "virtual" y "actual", ambos reales. El pasaje de lo virtual a lo real, que Deleuze denomina "actualización" o "efectuación", no es un pasaje cronológico, sino un salto entre dos dimensiones del tiempo que difieren por naturaleza. En el mismo sentido, Paz ha utilizado la palabra "encarnación" para referirse a este salto cualitativo entre dos temporalidades diferentes; así, a través de la poesía, el tiempo arquetípico encarna una y otra vez o, en términos deleuzianos, se actualiza. De ahí que Paz pueda definir la poesía como la "consagración del instante" (Paz, 2003, p. 51-75).

El tiempo mítico es tiempo en sí, tiempo en estado puro, eterno morir y recomenzar del tiempo. Los calendarios míticos, nos dice Octavio Paz, no tienen por objeto medir, sino ritmar el tiempo.

Si golpeamos un tambor a intervalos iguales el ritmo aparece como tiempo dividido en porciones homogéneas. La representación gráfica de semejante abstracción es la línea de rayas: --------. La intensidad rítmica dependerá de la celeridad con que los golpes caigan en el parche del tambor. A intervalos más reducidos corresponderá redoblada violencia. Las variaciones dependerán también de la combinación entre golpes e intervalos. Por ejemplo: - I---I-I---I-I--I-I-, etc. Aun reducido a este esquema, el ritmo es algo más que medida, algo más que tiempo dividido en porciones. La sucesión de tiempos y pausas revela una cierta intencionalidad, algo así como una dirección. El ritmo manifiesta una expectación, suscita un anhelar. Si se interrumpe sentimos un choque. Algo se ha roto. Si continua, esperamos algo que no acertamos a nombrar. El ritmo engendra en nosotros una disposición de ánimo que sólo podrá calmarse cuando sobrevenga "algo". Nos coloca en una actitud de espera. Sentimos que el ritmo es un ir hacia algo, aunque no sepamos qué pueda ser ese algo. Todo ritmo es sentido de algo. Así pues, el ritmo no es exclusivamente una medida vacía de contenido, sino tiempo original. (Paz, 2003, p. 79) 
Es interesante destacar que si bien el ritmo manifiesta una expectación, suscita un anhelar, se trata de un pretender sin objeto, puesto que los objetos pertenecen a la dimensión de lo claro y distinto. El mundo objetivo es un producto de la razón y supone ya haberle asignado un contorno a las cosas, es decir, los objetos pertenecen a la dimensión de las formas distintas mientras que el ritmo nos introduce en una dimensión sin distinciones. Por eso, el anhelar suscitado por el ritmo no tiene objeto, no procura nada en particular, sino que tiende a algo que no consigue definir.

Del mismo modo, si no es deseo de algo, tampoco es deseo de alguien, pues la dimensión pura del tiempo a la que el ritmo nos arrastra es anterior a la conciencia, por lo tanto, esa expectativa de la que nos habla Octavio Paz, no es sino una expectación pura.

Finalmente, la expectativa suscitada por el ritmo no expresa una falta que será satisfecha en el futuro, porque el tiempo en sí, que el ritmo evoca, no conoce pasado presente y futuro; es un tiempo sin distinciones, un tiempo todo. Al igual que para Kant o Bergson, para Paz, este tiempo arquetípico no forma parte del mundo sensible, sino que es una condición de posibilidad de ese mundo. El tiempo puro es una condición que no pasa, aunque haga posible el pasaje del tiempo empírico. El deseo que el ritmo suscita es independiente del futuro, de la conciencia y de los objeto; podría ser pensado, tal vez, al modo de Schopenhauer, como voluntad pura.

\section{Tercer movimiento: peso y suspensión}

Hasta donde es usual remontar la historia en búsqueda de las etimologías, vemos derivar la palabra pensamiento del verbo latino pendere ${ }^{l}$. Este verbo remite a dos acciones diferentes: la de pesar y la de pender, abriendo la posibilidad de considerar el asunto en dos direcciones: la primera ligada al peso, la segunda, a la suspensión o la liviandad.

En la primera dirección, pensar significa pesar, es decir, determinar lo que una cosa pesa. De ahí se deriva la posibilidad de sopesar, en el sentido de comparar el peso de diferentes cosas. Por último, habiendo determinado un peso, después otro, y habiéndolo comparado, es posible escoger entre ambos. ¿Cuánto pesa? ¿Cuál pesa más? ¿Cuál debo escoger? Así, determinar, distinguir y escoger, se entrelazan en un ejercicio sinérgico. Pensar será entonces sinónimo de distinguir, de determinar, según diferencias que permitirán y reclamarán una elección.

\footnotetext{
${ }^{1}$ Castello y Mársico, en su libro Oculto nas Palavras: Dicionário Etimológico para ensinar e aprender (2007) señalan: "el termino pensar proviene del latín pensare, que constituye una forma tardía derivada de pendere, con el sentido de 'pesar'. El sentido concreto convivió siempre con el abstracto, de modo que significó tanto el acto de determinar el peso, como el de 'evaluar', 'estimar' mentalmente, tal como en portugués utilizamos un compuesto de ese mismo verbo en la expresión 'sopesar alternativas'. 'Pensar' concentra pues un sentido originario que alude a un juicio evaluativo sobre el objeto del pensamiento".

En el Dictionnaire Étymologique du Français. (2002), de Picoche Picqueline se señala un camino semejante a partir de la palabra francesa pendre (suspender o estar suspenso). Pendre deriva, de la misma forma que el termino pensar, del latín pendere, pensus, cuyo sentido original es el de dejar pender "laisser pendre" (los platos de una balanza) de donde proviene el sentido clásico de pesar, evaluar (ponderar).

La imagen de la balanza sintetiza los dos caminos que he sugerido. En la idea de sopesar se evidencia la doble articulación, en el pensamiento, del peso y la suspensión.

Cabe mencionar que esa relación entre el peso y la suspensión en la etimología de la palabra pensamiento también ha sido señalada por Marilena Chauí, en su ya clásico libro Convite à filosofia. (1997, p. 153).
} 
En la codificación o estabilización de esas distinciones aparecen los criterios que permitirán encontrar el cribo, la medida, que establezca lo que pasa y lo que queda, lo que cuenta y lo que no cuenta, lo que vale la pena y lo que no la vale. Con su discusión y refinamiento el pensamiento alcanzará su dimensión crítica. Pensar críticamente significa establecer criterios de orden fundados en la medida, en la determinación.

Si tomamos el camino que lleva a la segunda acción derivada del verbo latino pendere, encontraremos que pensar significa pender. Estar pendiente, suspendido: en sobrevuelo. Fluctuando sobre una situación cualquiera, sin pronunciarse, sin posar en ella, sin escoger entre esto o aquello. Permaneciendo suspendido en la indistinción, en la ambigüedad. En ese sentido, pensar no es determinar; por el contrario, es mantenerse en la indeterminación.

Por otra parte, estar pendiente remite también a una expectativa. Como ocurre en una película de suspenso, donde la suspensión hace referencia a un estado de espíritu que implica un tender hacia algo que no puede ser determinado con claridad. Una atención, que es también una tensión y una extensión, un proyectarse en dirección a algo que no acertamos a definir.

Suspender, estar suspendido, pender, es mantener todas las posibilidades simultáneamente abiertas. Ni esto, ni aquello, sino lo indeterminado, lo indefinido, lo virtual. Ese "simultáneamente" marca un tiempo que no es sucesión cronológica, sino tiempo que no pasa, tiempo que dura. La suspensión nos coloca en una relación abierta con lo indeterminado.

\section{Cuarto movimiento: un sabio no tiene idea.}

El pensamiento occidental se estructuró en torno de la metáfora del peso y de la determinación. El principio de no contradicción constituyó el corazón de la racionalidad.

A partir del siglo XV la expansión colonial europea abre camino para la creación de un sistema-mundo, donde todas las culturas existentes serán interpretadas en función de una única cultura que funcionará como modelo. Así, se hace posible pensar una historia universal y un orden mundial que configura el tiempo y el espacio jerárquicamente. La representación del tiempo, continuo y sucesivo, gana entonces una nueva cualidad, transformándose en tiempo-progreso. Mediante una operación propia del universo colonial, el tiempo europeo pasa a ser concebido como presente en relación al tiempo de los colonizados, que será percibido como atraso. El presente de las colonias entonces pasará a coincidir con el pasado de Europa. Lo mismo acontece con el espacio: con la invasión de América el océano Atlántico gana una nueva importancia y brinda a Europa una centralidad que no tenía en el mundo antiguo, permitiendo pensar el resto del mundo como periferia.

A partir de esa nueva construcción geopolítica mundial el pensamiento occidental adquiere nuevas determinaciones. Al presentarse como modelo de todo pensar, concibe cualquier otra posibilidad como periférica y primitiva. De esa forma, el pensamiento que no se funda en el principio de no contradicción, dominante en occidente, es simplemente, tenido como pueril. El ápice de esta concepción colonial del pensamiento es quizás la historia de la filosofía de Hegel: que comienza por los chinos, para 
abandonarlos inmediatamente por considerar que en ellos sólo pueden encontrarse filosofemas, pero no una filosofía. Para Hegel, China se habría extraviado en un estadio primitivo del pensamiento, sin conseguir alcanzar el concepto. Sólo Europa, colocada en el siglo XIX como heredera natural del pensamiento griego, habría alcanzado un pensamiento maduro; el resto del mundo no tendría más que mitos, sabiduría o religión, formas primitivas del pensar que corresponderían a una prehistoria de la filosofía, a una pre-filosofía.

Pero, como afirma François Jullien (2000, p. 85-99), China conoció el principio de contradicción a través da la escuela de los Mozistas. El hecho de que este principio no se haya tornado dominante no autoriza a suponer una falta de potencia o una inmadurez de los pensadores chinos, del mismo modo que sería aventurado deducir la inferioridad del pensamiento de Heráclito por el hecho de que este no haya sido dominante en occidente. Sería más prudente considerar ambos caminos sin suponer jerarquías fáciles y buscar entender las razones por las cuales los sabios chinos desconfiaron de tal principio.

En su libro Un sabio no tiene idea, nos dice Jullien:

No tener idea significa que [el sabio] evita poner una idea adelante de otra - en detrimento de otra: no hay idea puesta en primer lugar, puesta en principio, sirviendo de fundamento, o simplemente de inicio, a partir del cual el pensamiento podría deducirse o, por lo menos, desarrollarse. (Jullien, 2000, p. $13)$.

El sabio teme ese poder ordenador de lo primero. Para que el mundo pueda continuar ofreciéndose es preciso renunciar a la arbitrariedad de una primera idea que sirva de fundamento al pensamiento. Pues, a partir de esa idea el pensamiento jamás dejaría de quedar preso a un punto de vista. Que el sabio no tenga idea significa decir que él no tiene ninguna idea privilegiada. No quiere colocar ninguna idea al inicio para que lo real conserve toda su virtualidad. El sabio quiere mantenerse disponible y para eso precisa no destacar ninguna idea. En eso radica su sabiduría.

Toda idea es una determinación y, por lo tanto, un recorte, una parcialidad. La filosofía nascería, precisamente, de esa parcialidad, de esa violencia que, al mismo tiempo que afirma una posibilidad, niega otro punto de vista. Es precisamente eso lo que obligaría a la filosofía a avanzar para corregir o compensar su parcialidad inicial. La filosofía es obligada a ir siempre hacia el frente, a pensar siempre de otra manera, refutando las ideas anteriores, según un principio beligerante que le es constitutivo; un juego agonístico que hace de los filósofos amantes, pretendientes y rivales. Por esto la filosofía se constituye como historia de sí.

La sabiduría, no proponiendo nada, no puede ser refutada, no hay en ella materia para el debate. No hay en ella nada a ser contestado y, por lo tanto, nada a esperar de ella, ninguna esperanza a ser depositada en el futuro. La sabiduría es, de ese modo, nos dice Jullien, la parte "anistórica" del pensamiento: ella es de todas las edades, viene del fondo de las edades, del fondo de inmanencia. De ahí su incurable banalidad. La sabiduría es irremediablemente rasa, en ella no hay nada eminente, nada interesante, nada a ser destacado, ningún secreto a ser descubierto, ningún significado oculto, ningún enigma a ser descifrado. Mantiene todo en el mismo plano. Por eso es tan difícil hablar de ella. 
La filosofía, por el contrario, como necesita siempre avanzar, precisa ser inventiva. Ella es constitutivamente insatisfecha. Hija de la falta y del deseo, la filosofía debe responder a un mundo concebido como enigma y a un pensamiento concebido como desciframiento. Infinita búsqueda de lo que está por detrás de las apariencias. Infinita deriva del significante. De ahí que la filosofía ame el peligro y la aventura, y también la conquista de la verdad. La filosofía no consigue pensar el movimiento sino a partir de la falta y del deseo. "Ora, el sabio no explora ni descifra, su propósito no está marcado por ningún deseo" (Jullien, 2000, p. 19). La sabiduría es pura superficie, ella no tiene profundidad, de ahí que Oriente no valorice la duda ni el cuestionamiento. En ella no hay enigma. Nada a descubrir. Nada a ser develado. Todo es evidente y esa evidencia viene a nosotros en el mismo plano. Por eso nos resulta, en cierto modo incomprensible: nada más difícil que mantener el pensamiento abierto, en la intemperie, sin el apoyo de una idea verdadera, de la cual el pensamiento pueda partir y en la cual pueda resguardarse; nada más difícil que mantener el pensamiento en suspensión, indeterminado.

La sabiduría no se apoya en el concepto, mucho menos en la verdad, ella no quiere determinar, no pretende decir dónde está la verdad, ni cómo encontrarla. Si los sabios chinos rechazaron la lógica identitaria, que se funda en la no contradicción, fue, según Jullien, para resguardarse de la parcialidad que acompaña toda determinación. Antes que fijar una posición ellos prefirieron recrear a cada instante una disposición. Por eso, el sabio no quiere la verdad, él quiere mantener el pensamiento disponible. Por eso, la sabiduría no da lugar al progreso, sino a la variación. Ella es fluctuante: "Los chinos tienen otro decir: la sabiduría no se explica (ella no da a entender), ella es para ser meditar o, mejor todavía, dando todo el tiempo necesario a ese despliegue, como si fuese el de una impregnación, para ser 'saboreada' ". (Jullien, 2000, p. 20).

El ritmo no sólo es el elemento más antiguo y permanente del lenguaje. Como dice Octavio Paz, él es también el elemento genético del pensamiento. Pues el pensamiento nace del ritmo, o incluso, es el propio ritmo. La disposición de ánimo que el ritmo suscita, ese tender, ese extenderse en dirección a algo que no acertamos a nombrar, esa abertura a lo indeterminado es la condición primera del pensamiento. Nosotros mismos somos ese ritmo. Antes de nuestra historia personal y nuestras señas particulares, antes de nuestra conciencia, somos una disposición, una expectación, un sentido. A veces lo olvidamos, pero cuando una palabra, por el poder que el ritmo le confiere, nos hiere de muerte, nos suspende el aliento y nos hace devenir un ritmo, que es, simultáneamente, sentido y sentimiento, entonces... entonces... sentimos que las ideas riman. Entrevemos que pensamientos y frases son también ritmos, llamadas, ecos. Sentimos que pensar es dar una nota justa y comprendemos, súbitamente, que el diálogo no es un acuerdo, sino un acorde.

\section{Referencias Bibliográficas}

ARISTÓTELES. Física. Trad. Cast. Alejandro Vigo. Buenos Aires: Biblos, 2001. CASTELLO, L. e MÀRSICO, C. Oculto nas Palavras: Dicionário Etimológico para ensinar e aprender. Belo Horizonte: Autêntica, 2007.

CHAUÍ, Marilena. Convite à Filosofia. São Paulo: Ática, 1997. DELEUZE, Gilles. Diferencia e repetição. Rio de Janeiro: Graal, 1968/1988. 
Lógica do sentido. São Paulo: Ed. Perspectiva, 2000.

O bergsonismo. São Paulo: Ed. 34, 1999.

JULLIEN, François. O sábio não tem idéia. São Paulo: Martins Fontes, 2000.

PAZ, Octavio. El arco y la lira. En: Obras completas. Tomo I.. México: Fondo de Cultura Económica, 2003.

PICQUELINE, Picoche. Dictionnaire Étymologique du Fraçais. Paris: Le Robert, 2002. 